\title{
Locus equations as phonetic descriptors of consonantal place of articulation
}

\author{
HARVEY M. SUSSMAN and JADINE SHORE \\ University of Texas, Austin, Texas
}

\begin{abstract}
This experiment tested whether locus equation coefficients, slope, and $y$-intercept could serve as indices of place of articulation for obstruents sharing the same place of articulation across different manner classes. Locus equations for 22 speakers were derived from $\mathrm{CV} / \mathrm{t} /$ words with initial voiced stop /d/, voiceless aspirated stop $/ \mathrm{t} /$, nasal $/ \mathrm{n} /$, voiced fricative $/ \mathrm{z} /$, and voiceless fricative $/ \mathrm{s} / \mathrm{preceding} 10$ vowel contexts. Post hoc tests revealed $/ \mathbf{d} /=/ \mathbf{z} /=/ \mathbf{n} /$ for slope means. Voiced $/ \mathrm{d} /$ and voiceless $/ \mathrm{t} /$ were also equivalent when $F 2$ transition onset measurement points were equated. Scatterplots of locus equation coefficients revealed three nonoverlapping and distinct clusters when the diverse coronal group was compared with labials and velars. A discriminant analysis using slope and $y$-intercept as predictors successfully categorized all five coronals into one alveolar group with $87.1 \%$ accuracy. The collective results support the contention that locus equations can serve as effective phonetic descriptors of consonant place of articulation across manner classes.
\end{abstract}

Locus equations are linear regressions of the onset of $F 2$ transitions on their offsets measured in the vowel nucleus (Lindblom, 1963). Frequency coordinates coding $F 2$ transitions of allophonic variants of a given stop place category (e.g., beat, bet, bat, boot, but, boat, bought, bait, etc.) tightly cluster about regression lines that significantly vary as a function of stop place of articulation (Sussman, Hoemeke, \& Ahmed, 1993; Sussman, McCaffrey, \& Matthews, 1991). The vowel-context induced variability of the $F 2$ transition, so evident when individual tokens are compared, gives way, when displayed as locus equation plots, to a lawful acoustic representation of the entire stop place category. The $x, y$ coordinates of locus equation scatterplots align themselves in a highly correlated and linear fashion around the regression line. This orderly plot captures a higher order and emergentlike acoustic commonality - namely, a vowel normalization of the $F 2$ transition within each stop place category. Higher order locus equation coefficients - slope and $y$ intercept-when serving as predictor variables in a discriminant analysis, were shown to correctly classify labial, alveolar, and velar stop place of articulation with $100 \%$ accuracy (Sussman et al., 1991). Celdran and Villalba (1995) have recently replicated this result for Spanish stops. Ten speakers produced stimulus words containing $/ \mathrm{p} /, / \mathrm{b} /, / \mathrm{t} /, / \mathrm{d} /, / \mathrm{k} /$, and $/ \mathrm{g} /$ preceding five vowel contexts. With either slope alone or slope and $y$-intercept as predictors, the correct classification rates were $100 \%$ for all three place of articulation categories. Place information is inherently encoded by locus equations because

This research was supported by Grant R01 DC2014-01A1 from the National Institute on Deafness and Other Communication Disorders. Correspondence should be addressed to H. M. Sussman, Department of Linguistics, University of Texas, Austin, TX 78712 (e-mail: sussman@, mail.utexas.edu). the slope of the regression function is proportional to the extent of CV coarticulation being used by the speaker (see Figure 10 in Sussman et al., 1993). The consistently linear scatterplots, as documented across languages, gender, and speaking conditions, have recently been interpreted as possibly serving a functional role in speech perception and the representational encoding (viz., mapping) of acoustic-based place of articulation categories (Sussman, Fruchter, \& Cable, 1995).

The acoustic correlates of consonantal place of articulation, however, are many and varied. Burst information, onset spectra, and formant transition motion have all been implicated, to greater or lesser extents, as perceptual cues for place of articulation (see, e.g., Blumstein \& Stevens, 1979, 1980; Dorman, Studdert-Kennedy, \& Raphael, 1977; Eek \& Meister, 1995; Furui, 1986; KewleyPort, 1983; Lahiri, Gewirth, \& Blumstein, 1984; Nossair \& Zahorian, 1991; Ohde, Haley, Vorperian, \& McMahon, 1995; Walley \& Carrell, 1983). Locus-equation-based analyses can offer additional insights into the role of the $F 2$ transition onset-offset combination as a contributing cue for consonant place of articulation. Though the taxonomic value of locus equations to date has primarily been as a phonetic descriptor of stop place of articulation, the perceptual relevance of locus equations has also been shown. Fruchter (1994) demonstrated that the relationship between $F 2$ onset and $F 2$ vowel could be of use during speech perception. Fruchter orthogonally varied $F 2$ onset frequencies in .25 Bark steps across 10 vowel contexts in synthesized (five formants) CV syllables with no burst. Stimuli were presented to listeners for identification, and identification frequencies were then tabulated and pooled across subjects $(N=3)$ to yield stepped grayscale displays (similar to the amplitude $[z]$ axis of a spectrogram) interpretable as "identification surfaces" for each stop place of articulation. The darkest regions cor- 
responded to the highest frequencies of consensus identification across pooled subject data, and the lightest regions reflected more ambiguous zones of perceptual space. Token-level acoustic data were then superimposed over the grayscale perceptual surfaces. The overlays allowed appraisal of the correspondences between the distribution of the acoustic data and features of the perception data. There were clear "peaks" in the three identification surfaces (darkest areas) where a given stop consonant perception dominated and correspondences between the acoustic coordinates from production to these perception peaks, especially for $/ b /$ and $/ d /$, but less so for velar $/ g /$, which is more dependent on the presence of a burst for identification. In areas of acoustic overlap, there were clear dominance effects in perception; that is, a " $b$ " identification prevailed when tokens fell in the region of $/ b /$ and /d/ overlap in front vowel space, and a " $\mathrm{d}$ " identification prevailed when tokens fell in the region of $/ \mathrm{d} /$ and $/ g /$ overlap in back vowel space.

The Fruchter (1994) study provides the first empirical evidence that locus equations possess psychological reality. $F 2$ onset, operating in a relational and combinatorial sense with $F 2$ vowel, can provide a significant cue for stop consonant place of articulation. Interestingly, computational experiments in which time-delayed neural networks were fed sampled spoken CV wave forms, tasked to classify initial consonant by place of articulation, and then analyzed to determine which parts of the input signal were most effective for the task showed that the parts of the signal most informative about consonantal place of articulation were the $F 2$ onset and $F 2$ vowel frequencies (Hinton \& Lang, 1988; McDermott \& Katagiri, 1988; Tank \& Hopfield, 1988; Waibel, Hanazawa, Hinton, Shikano, \& Lang, 1987; Watrous, 1988).

Of considerable interest to phoneticians and speech theorists is the ability of the locus equation metric to serve as a general phonetic descriptor for consonant place of articulation when a given place feature spans diverse manner classes. Studies directly comparing acoustic characteristics of homorganic consonants are limited. Sussman (1994) investigated unaspirated voiceless stops, nasals, fricatives, and approximants in 14 speakers of American English. Ten medial vowels (/i i e æ $\mathfrak{\varepsilon}$ a u o $\Lambda$ ऽ/) were used with the following syllable-initial consonants: $/ \mathrm{m} \mathrm{n}$ $\mathrm{vzz}_{3} \partial \mathrm{w} \mathrm{j} \mathrm{r} /$ as well as $/ \mathrm{p} \mathrm{t} \mathrm{k} /$ in initial $/ \mathrm{sC} /$ clusters. In a plot of locus equation coefficients, with slope plotted on the $x$-axis and $y$-intercept on the $y$-axis, consonants sharing similar place features but various manner classes clustered together in several nonoverlapping distributions. Specifically, a coronal group consisting of $/ \partial \mathrm{d} t \mathrm{n}$ $\mathrm{z}_{3}$ / formed one cluster, a velar group (/g k/) formed another cluster, and a labial/labiodental group (/b p m v/) formed a distinct and nonoverlapping third cluster. Approximants formed their own cluster with all slopes near zero, but varying $y$-intercepts that reflected differences in $F 2$ onset loci effectively contrasting among $/ \mathrm{w} \mathrm{l} \mathrm{j} /$. No statistical comparisons were performed in this preliminary study among obstruents having the same place of articulation but belonging to different manner classes.
Fowler (1994) also extended the locus equation metric beyond voiced oral stops to investigate place of articulation across manner classes. Arguing that "any invariant for stop place must be an invariant for place of articulation in general" (p. 598), Fowler compared locus equation slopes for stops and fricatives varying along a place continuum - / $\mathrm{b} \mathrm{\gamma z} 3 \mathrm{~g} /$ in 10 speakers. In the single test case when two consonants with the same place of articulation but different manner classes were compared, the slope for $/ \mathrm{d} /(.47)$ was reported to be significantly different from the slope for $/ z /(.42)$, and hence it was concluded that "locus equations provide poor information for place" (p. 605). Mean $y$-intercept values were not significantly different in the $/ \mathrm{d} /(1120 \mathrm{~Hz})$ versus $/ z /(1078 \mathrm{~Hz})$ statistical analysis.

A better test of whether or not locus equations can serve as phonetic descriptors of consonant place of articulation across manner class would be to jointly use slope and $y$ intercept as codependent variables in a multivariate analysis. Locus equation slope, by itself, is proportional to the extent of coarticulation existing between the vowel and preceding consonant (Krull, 1989; Sussman, Hoemeke, \& McCaffrey, 1992). While coarticulatory factors may be expected to differ across manner classes (cf. Recasens, 1989), differences in tongue body position that accommodate subtle differences in the formation of the consonantal constriction also can be expected to contribute to overall $F 2$ differences. In Fowler (1994), the posterior progression from labiodental $/ v /$ to interdental $/ \delta /$ to alveolar $/ z /$ to palatal $/ 3 /$ was captured by changing slope and $y$-intercept values as slopes systematically decreased (.73 to .50 to .41 to .34 ) and $y$-intercepts systematically increased ( 337 to 903 to 1078 to $1408 \mathrm{~Hz}$ ) as a function of fricative place of articulation. While slope and $y$-intercept are inversely correlated in that steep slopes tend to have low $y$-intercepts and shallow slopes have higher $y$-intercepts, two nonoverlapping scatterplots can have similar slopes and contrast only in $y$-intercepts, as is seen in coronal stop contrasts involving secondary articulations such as pharyngealization (in Cairene Arabic) and retroflexion (Urdu) as reported by Sussman et al., 1993.

Using data from both Sussman (1994) and Fowler (1994), as well as synthetic VCVs (where C varied across labial, alveolar, and velar place) produced by the distinctive region model (Carré \& Mrayati, 1992), Chennoukh, Carré, and Lindblom (1995) concluded that higher order locus equation coefficients were fairly constant descriptors of place of articulation for homorganic consonants spanning oral, nasal, fricative, and voicing manner classes.

The following study is a replication and extension of Fowler (1994), carried out with an expanded phonetic inventory and a larger speaker population, to determine whether locus equations can serve as a general phonetic descriptor of consonant place of articulation. Syllableinitial consonants spanning five different manner classes, but each having the same alveolar place feature, were compared: voiced stop $/ d /$, nasal $/ n /$, voiceless aspirated stop $/ \mathrm{t} /$, voiced fricative $/ \mathrm{z} /$, and voiceless fricative $/ \mathrm{s} /$. If locus 
equations function as a phonetic descriptor of consonantal place of articulation, one would expect nonsignificant statistical differences for slopes and $y$-intercepts across all coronals. If nasality, frication, aspiration, and continuancy interact with $F 2$ trajectories in as yet unforeseen ways, a softer prediction would hold that, as a class, coronals would evidence slope and $y$-intercept coefficients that would basically cluster together despite manner class-induced variation, but be sufficiently contrastive vis à vis labial and velar places of articulation. The purpose of this study was to determine how well locus equations hold up as general place descriptors when compared across the robust articulatory and sound source differences characterizing various manner classes of consonatal production.

\section{METHOD}

\section{Subjects and Stimulus Materials}

Twenty-two male speakers were recruited for this study. All subjects were volunteers and ranged in age from 19 to 55 , with a mean age of 34.6. All subjects had normal hearing and were monolingual speakers of American English. Since all previous locus equation studies have shown no significant effect of gender, male speakers were chosen simply to maximize the ease of making measurements from spectrographic displays. Several dialectal variations were present in the subject pool including that of Texans with fronted $/ u / s$ having $F 2$ resonances in the vicinity of $1400-2000 \mathrm{~Hz}$.

Within coronals, there are several consonants belonging to different manner classes that have an alveolar place of articulation $(/ \mathrm{d}$ $\mathrm{t} \mathbf{n ~ z ~ s}$ /). Although these consonants can exhibit assimilation with a following consonant that can shift the place of articulation anteriorly to interdental (e.g., $/ \mathrm{n} /$ in tenth, $/ \mathrm{d} /$ in hundredth) or posteriorly to postalveolar (e.g., /n/ in inch, /d/in edge) (Clements, 1985), in a $\mathrm{CV} / \mathrm{t} /$ context all consonants have a relatively stable alveolar place of articulation affected only by the following vowel context. Monosyllabic test words were produced within the sentence frame: "Say CV/t/ again." Each test word was repeated five times as the 10 vowels in medial position were randomized in five different orderings for each consonant. The five randomized word lists per consonant were printed on a single sheet and read by the speaker at a comfortable loudness level and pace. The vowels used, identical to those in Sussman and colleagues (Sussman et al., 1995; Sussman et al., 1993; Sussman et al., 1991), were /i i e $\varepsilon \mathfrak{x}$ a o u $\Lambda \mathrm{o} /$. The ordering of consonants was also randomized across speakers. Thus, a total of 250 tokens were analyzed for each speaker ( 5 consonants $\times 10$ vowel contexts $\times 5$ repetitions), and each locus equation regression function was generated by using all 50 tokens (10 vowels $\times 5$ repetitions) per consonant. In all, 5,500 tokens were acoustically analyzed in this study.

\section{Procedure}

All analysis procedures and measurements were identical, insofar as possible, to those previously described in Sussman and colleagues (Sussman et al., 1995; Sussman et al., 1993; Sussman et al., 1991). All subjects were recorded in a soundproof room (IAC) using a high-quality microphone (Electro-Voice RE 15) and a Marantz cassette tape recorder (Model PMD 201). The recorded signal was sampled at $10 \mathrm{kHz}$, digitized, and filtered with an Apple Macintosh IIci computer with MacAdios II hardware. The MacSpeech Lab II software package (Version 1.8, G.W. Instruments) was used for all display, editing, playback, and measurement procedures. $F 2$ onsets $(\mathrm{Hz})$ were obtained solely from cursor readouts placed on wideband spectrogram displays. High-resolution expansions of the portions of the spectrograms in the vicinity of the $\mathrm{CV}$ interface were routinely performed to aid visualization of $F 2$ onset at the first glottal pulse of the vowel and in the noise source portions of aspirated stops. Formant measurements for $F 2$ vowel were obtained from three sources: direct cursor readouts from wideband spectrogram displays, linear predictive coding (LPC), and fast Fourier transforms (narrowband FFTs). A default parameter of 13 coefficients was used for the autocorrelation function for LPC analysis. When LPC and FFT spectra were obtained from midvowel target loci, the time marker in the center of the analysis window coincided to within a millisecond to the time point sampled by the (mousecontrolled) cursor frequency from the on-screen spectrogram. The mean $F 2$ value from the three measures (spectrogram, LPC, FFT) taken at a midvowel site was used as the independent variable, $F 2$ vowel, in the regression analyses. The average variation across the three measurements for $F 2$ vowel was $83.6 \mathrm{~Hz}$.

\section{Data Sampling Points}

Measurement loci for $F 2$ vowel were exactly the same as described in Sussman et al. (1991). Briefly, criteria for $F 2$ vowel placement were as follows: (1) if the $F 2$ resonance was steady state or diagonally oriented, the midpoint of the formant was taken on the basis of visual inspection; (2) if the $F 2$ resonance was U-shaped or the inverse, the "minima/maxima" point was taken as the vowel target frequency. Although criteria for midvowel formant measurement loci were visually determined, no sample points from what might be considered the vowel off-glide were taken, and for diphthongs the measurement point was always taken within the initial vowel segment.

$F 2$ onset measurement points for $/ \mathrm{d} /, / \mathrm{n} /, / \mathrm{z} /$, and $/ \mathrm{s} /$ were the frequency of $F 2$ at the first glottal pulse of the vowel after (1) the release burst for $/ d /$, (2) the cessation of nasal resonances for $/ n /$, (3) the cessation of high-frequency frication for $/ \mathrm{z} /$ and $/ \mathrm{s} / . F 2$ onset point for $/ \mathrm{t} /$ had to be modified to take into consideration the lengthy aspiration period following stop release. Figure 1 (top) shows a representative spectrogram for / $\mathrm{t} /$ (in the word taught); the bottom spectrogram shows daught produced by the same speaker. If the standard procedure for taking $F 2$ onsets was followed for $/ \mathrm{t} /$, the first glottal pulse would be approximately at vowel midpoint, and a very steep locus equation scatterplot would result, because " $F 2$ onsets" would be, in effect, similar to $F 2$ vowel. To establish, as close as possible, comparable measurement loci for $F 2$ onsets in aspirated /t/ vis à vis $/ \mathrm{d} /$, the $F 2$ resonance of the vowel was tracked back through the aspiration period by using a high-resolution setting (screen width $=100 \mathrm{msec}$ ). The earliest visible $F 2$ resonance, subsequent to burst release, that was judged to continue into the $F 2$ of the vowel was taken as $F 2$ onset. The arrow shows the $F 2$ resonance that would be measured as $F 2$ onset for $/ \mathrm{t} /$ in taught. Obviously, this value, at approximately $2000 \mathrm{~Hz}$, is quite different from the onset frequency that would be obtained if the initial glottal pulse (at approximately $1100 \mathrm{~Hz}$ ) was taken as $F 2$ onset. To establish a more valid comparison to / $/$ / a second category for /d/ was also used which took, as $F 2$ onset, not the first glottal pulse, as traditionally measured (Lindblom, 1963), but rather the earliest prominent resonance of $F 2$ during the brief VOT interval following the burst (and preceding onset of vocal fold vibration). The arrow in Figure 1 (bottom) for daught shows the $F 2$ onset measurement point that would be taken for this "special" category of $/ d /$. It can be seen that the resonance pulse taken as $F 2$ onset during the VOT interval in daught is higher (over $100 \mathrm{~Hz}$ ) than the traditionally taken point for voiced stops. It was felt that this methodological procedure for obtaining/d/ onsets created a more equivalent phonetic comparison for $/ d /$ versus $/ t /$. Thus, two distinct locus equations were generated for $/ \mathrm{d} /$, a standard plot with $F 2$ onset taken at the first glottal pulse corresponding to the initial pitch period of the vowel and a nontraditional, but perhaps more phonetically valid, locus equation, ${ }^{1}$ where $F 2$ onset was taken 

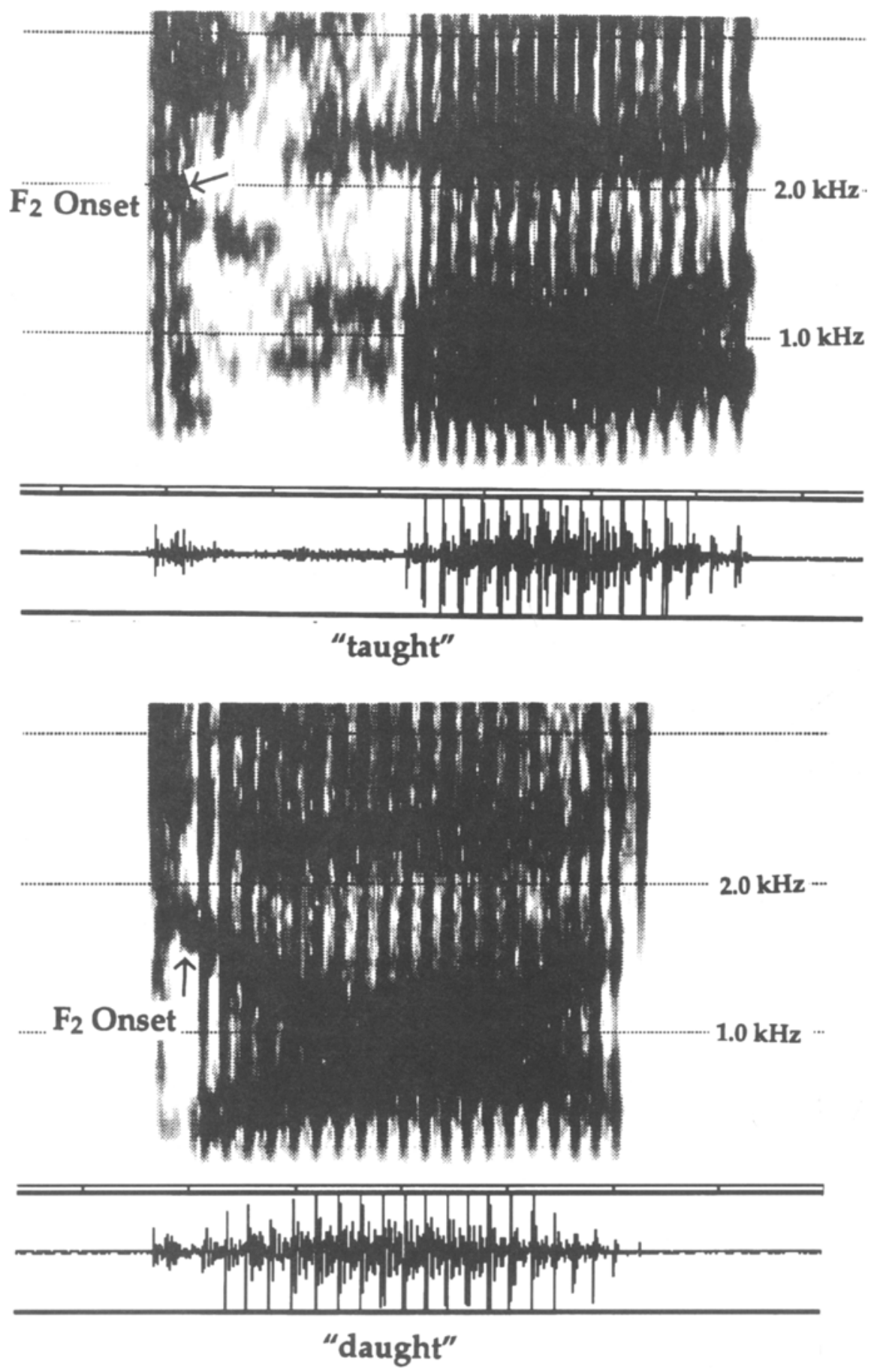

Figure 1. Top: spectrogram of the word taught, showing appearance of $F 2$ resonance throughout the aspiration interval; the arrow shows the place where $F 2$ onset was measured for aspirated / $t$ / tokens. Bottom: spectrogram of the word daught for the same speaker, showing the presence of an $F 2$ resonance pulse during the brief VOT interval following the $/ \mathrm{d} /$ burs $i$; the arrow shows where $F 2$ onset was measured for the category /d/ @ burst.

after the release burst, but before glottal pulsing began for the vowel. This $/ \mathrm{d} /$ will be noted as $/ \mathrm{d} / @$ burst in the data tables to follow.

A brief note should be made at this point that taking $F 2$ onset at the first glottal pulse corresponding to vowel onset for $/ z /, / \mathrm{s} /$, and $/ \mathbf{n} /$, while unavoidable at present, is not, strictly speaking, the most accurate measurement point to assess where place-related $F 2$ acoustic resonances first arise. The long frication interval of $/ \mathrm{s} /$ and $/ z /$ often contained a clearly visible noise-supported resonance of $F 2$ that could be traced back to the beginning of the consonant. However, since this $F 2$ resonance onset point was not consistently and unequivocally determinable during the noise excitation for the fricatives and the nasal murmur of $/ \mathbf{n} /$, only traditionally defined $F 2$ onset points were taken for $/ \mathrm{z} /, \mathrm{s} /$, and $/ \mathrm{n} /$. 


\section{Interjudge Reliability}

To test for reliability of formant measurements, especially $F 2$ onsets taken during the aspiration interval (/t/ and $/ \mathrm{d} / @$ burst), investigator J.S. remeasured data originally measured by investigator H.M.S. A speaker was selected at random (Speaker 17), and all tokens across all five consonants were remeasured and compared $(N=$ 250 ). In the replication, $F 2$ onsets were taken, as described above, from cursor placement on high-resolution wideband spectrogram displays, and $F 2$ vowel was obtained by averaging three midpoint frequencies from three convergent sources (wideband spectrogram, LPC, and narrowband FFT) for each token. Both correlations and absolute frequency differences were obtained in the reliability analysis. While correlational analyses can be somewhat misleading in assessing reliability, the following Pearson correlation coefficients were obtained for $F 2$ onsets: $/ \mathrm{d} /=.98 ; / \mathrm{d} / @$ burst $=.75 ; / \mathrm{t} /=.71$; $|\mathrm{z}|=.95 ; / \mathrm{s} /=.98 ; / \mathrm{n} /=.94$. Across all five obstruents, the correlation between the two investigators' measurements was 887 . F2 vowel correlation coefficients for each consonant were as follows: $/ \mathrm{d} /=.98 ; / \mathrm{t} /=.99 ; / \mathrm{z} /=.98 ; / \mathrm{s} /=.99 ; / \mathrm{n} /=.98$. The absolute frequency differences across the two measurements is a better indicator of test-retest reliability. The mean (absolute) frequency difference calculated across the 50 tokens per consonant were as follows: $F 2$ onset- $/ \mathrm{d} /=67.3 \mathrm{~Hz} ; / \mathrm{d} / @$ burst $=63 \mathrm{~Hz} ; / \mathrm{t} /=74.8 \mathrm{~Hz} ; / \mathrm{z} /=$ $72.3 \mathrm{~Hz} ; / \mathrm{s} /=99.3 \mathrm{~Hz} ; / \mathbf{n} /=85.5 \mathrm{~Hz}$. The overall mean difference between the two measures across all consonants was $77 \mathrm{~Hz} . F 2$ vowel differences across all five consonants were as follows: $/ \mathrm{d} /=$ $70 \mathrm{~Hz} ; / \mathrm{t} /=65.4 \mathrm{~Hz} ; / \mathrm{z} /=85.6 \mathrm{~Hz} ; / \mathrm{s} /=72 \mathrm{~Hz} ; / \mathbf{n} /=71.2 \mathrm{~Hz}$. The overall $F 2$ vowel mean (absolute) difference was $72.8 \mathrm{~Hz}$. These relatively small frequency differences compare very favorably with the result of a recent study comparing agreement between automatic and manual formant measurements, where $82 \%$ of the tokens were reported to be within $200 \mathrm{~Hz}$ (Hasegawa-Johnson, 1995). Although automatic versus manual comparisons are not the same as manual versus manual, the point emphasized is that $200 \mathrm{~Hz}$ was taken as an acceptable benchmark for agreement across measurement procedures. Most importantly, locus equation slopes and $y$-intercepts across the two investigator measurements were in close agreement. The mean slope difference across the five consonantal categories was .039 , with a mean $y$-intercept difference of only $60.6 \mathrm{~Hz}$.

\section{RESULTS}

The slopes and $y$-intercepts of locus equations obtained for each manner class obstruent across the 22 speakers are shown in Table 1. Each slope/y-intercept characterizes the regression line fit to the scatterplot of all 50 tokens per consonant ( 10 vowels $\times 5$ repetitions). Figure 2 shows representative locus equation plots for the stop, nasal, and fricative obstruents of this study (Speaker 6). It can be seen that all scatterplots have data points tightly clustered along the regression line giving an extremely linear form to the scatterplot comprising each manner class category. The slope and $y$-intercept values were entered into a doubly-dependent multivariate analysis. This MANOVA yielded a significant effect for manner class $[F(10,208)=68.31, p<.001]$. Differences between means were examined with Scheffe tests, and the results of these tests are shown separately for slope and $y$-intercept in Table 2. Four mean slope comparisons were nonsignificant: $/ \mathrm{d} /$ versus $/ \mathrm{n} /, / \mathrm{d} /$ versus $/ \mathrm{z} /, / \mathrm{d} / @$ burst versus $/ \mathrm{t} /$, and $/ \mathrm{n} /$ versus $/ \mathrm{s} / .^{2}$ Thus, several locus equation slopes generated from utterances with the same place of articulation and spanning several manner classes (voicing, nasality, and frication) were similar. The three voiced obstruents— $/ \mathrm{d} /, / \mathbf{n} /$, and $/ \mathbf{z} /$ - had statistically similar slopes, and when $F 2$ onsets for $/ \mathrm{d} /$ were taken at the first visible

Table 1

Summary of Locus Equation Slopes and $y$-Intercepts Across Consonant Manner Classes for Each Speaker

\begin{tabular}{|c|c|c|c|c|c|c|c|c|c|c|c|c|}
\hline \multirow[b]{3}{*}{ Speaker } & \multicolumn{12}{|c|}{ Consonant Manner Classes } \\
\hline & \multicolumn{2}{|c|}{$/ \mathrm{d} /$} & \multicolumn{2}{|c|}{ /d/@burst } & \multicolumn{2}{|c|}{$/ \mathrm{t} /$} & \multicolumn{2}{|c|}{$/ \mathbf{n} /$} & \multicolumn{2}{|c|}{$\mid z /$} & \multicolumn{2}{|c|}{$/ \mathrm{s} /$} \\
\hline & $k$ & $c$ & $k$ & $c$ & $k$ & $c$ & $k$ & $c$ & $k$ & $c$ & $k$ & $c$ \\
\hline 1 & .47 & 903 & .23 & 1439 & .17 & 1528 & .66 & 502 & .33 & 1033 & .63 & 559 \\
\hline 2 & .48 & 1000 & .35 & 1393 & .26 & 1591 & .49 & 1053 & .42 & 938 & .67 & 541 \\
\hline 3 & .41 & 938 & .23 & 1357 & .29 & 1365 & .45 & 810 & .32 & 906 & .55 & 570 \\
\hline 4 & .23 & 1517 & .15 & 1687 & .10 & 1829 & .40 & 1104 & .42 & 893 & .66 & 468 \\
\hline 5 & .37 & 1172 & .25 & 1484 & .15 & 1679 & .55 & 742 & .38 & 871 & .53 & 736 \\
\hline 6 & .46 & 1003 & .28 & 1439 & .31 & 1435 & .48 & 918 & .42 & 792 & .61 & 570 \\
\hline 7 & .53 & 923 & .38 & 1256 & .28 & 1377 & .61 & 680 & .43 & 860 & .69 & 465 \\
\hline 8 & .37 & 1171 & .25 & 1414 & .21 & 1541 & .42 & 1019 & .38 & 913 & .65 & 513 \\
\hline 9 & .31 & 1217 & .28 & 1410 & .28 & 1360 & .60 & 620 & .52 & 710 & .67 & 475 \\
\hline 10 & .40 & 1041 & .25 & 1425 & .23 & 1434 & .30 & 1180 & .40 & 865 & .58 & 569 \\
\hline 11 & .30 & 1287 & .21 & 1498 & .20 & 1675 & .37 & 1044 & .21 & 1104 & .32 & 976 \\
\hline 12 & .37 & 1244 & .26 & 1443 & .22 & 1566 & .45 & 986 & .34 & 997 & .53 & 714 \\
\hline 13 & .42 & 1118 & .22 & 1515 & .34 & 1338 & .39 & 1115 & .40 & 993 & .54 & 732 \\
\hline 14 & .49 & 983 & .33 & 1277 & .22 & 1494 & .49 & 866 & .30 & 1004 & .65 & 460 \\
\hline 15 & .42 & 1149 & .29 & 1412 & .27 & 1424 & .48 & 998 & .34 & 1167 & .50 & 833 \\
\hline 16 & .38 & 1248 & .28 & 1409 & .21 & 1542 & .42 & 1106 & .34 & 1088 & .51 & 775 \\
\hline 17 & .33 & 1371 & .20 & 1628 & .24 & 1557 & .37 & 1216 & .26 & 1237 & .42 & 1041 \\
\hline 18 & .53 & 979 & .31 & 1352 & .34 & 1314 & .49 & 943 & .45 & 954 & .72 & 476 \\
\hline 19 & .38 & 1006 & .21 & 1275 & .31 & 1192 & .52 & 706 & .42 & 823 & .55 & 655 \\
\hline 20 & .37 & 1089 & .20 & 1362 & .19 & 1439 & .58 & 631 & .43 & 692 & .53 & 536 \\
\hline 21 & .37 & 1202 & .21 & 1539 & .11 & 1794 & .49 & 866 & .39 & 967 & .45 & 853 \\
\hline 22 & .47 & 1007 & .40 & 1184 & .24 & 1417 & .57 & 678 & .42 & 915 & .57 & 631 \\
\hline$M$ & .40 & 1117 & .26 & 1418 & .23 & 1495 & .48 & 899 & .38 & 942 & .57 & 643 \\
\hline$S D$ & .075 & 158 & .062 & 117 & .066 & 156 & .089 & 203 & .068 & 134 & .097 & 169 \\
\hline
\end{tabular}

Note- $k$, slope; $c, y$-intercept (in Hertz). 

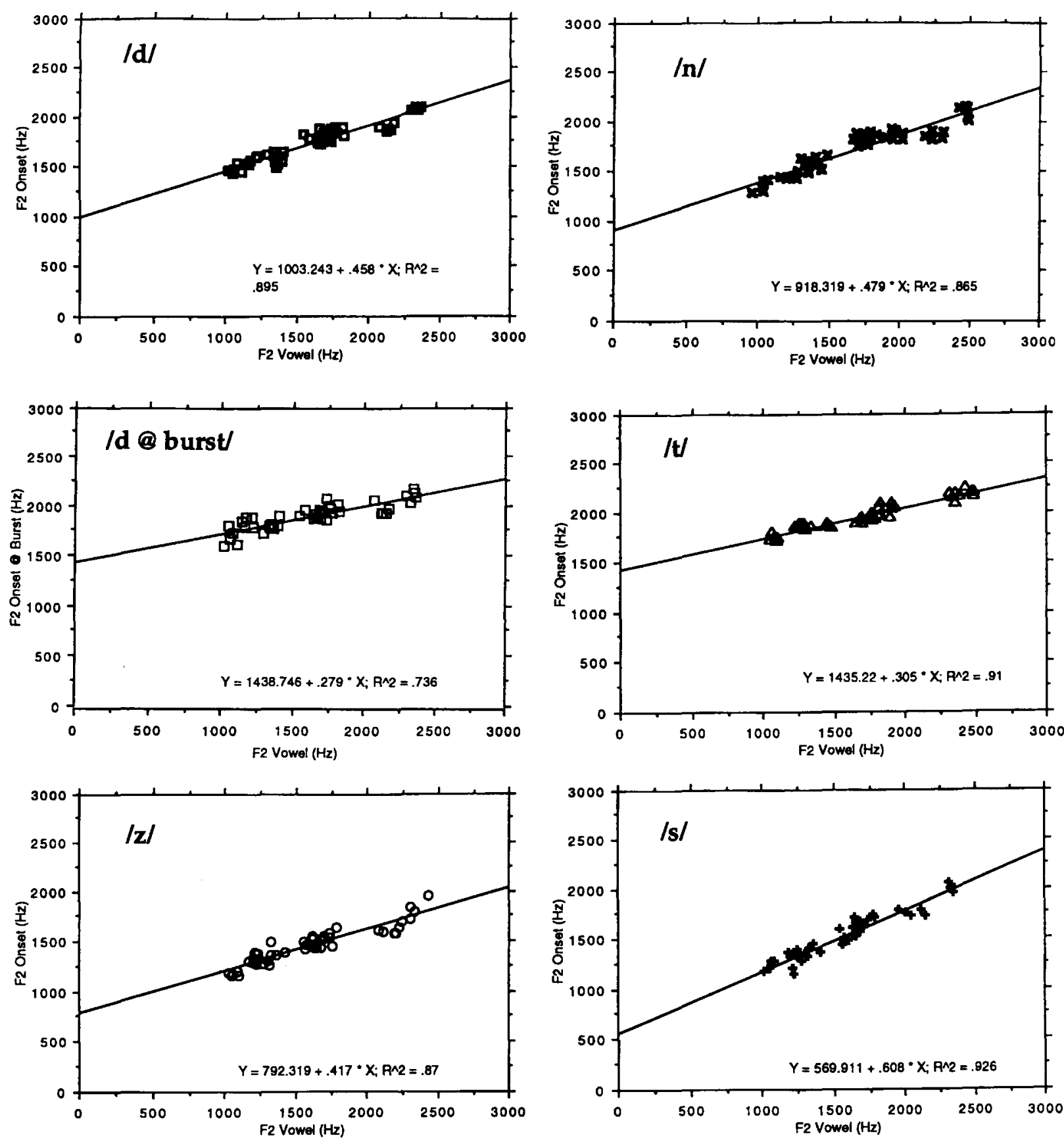

Figure 2. Representative locus equation scatterplots (from Speaker 6) for the five coronal obstruents examined. All regression fits were made to the 50 tokens constituting each consonantal category.

resonance during the brief aspiration interval there was no difference in slope as a function of voicing $(/ \mathrm{d} / @$ burst = $.26 \mathrm{vs} . / \mathrm{t} /=.23)$. Nasal $(/ \mathrm{n} /=.48)$ and voiceless fricative $(/ \mathrm{s} /=.57)$ slope means were also statistically nonsignificant. Manner class did result in significant slope differences when voiceless aspirated $/ t /$ was compared with all other consonants (except that $/ \mathrm{d} / @$ burst) and voiceless $/ \mathrm{s} /$ slopes were significantly higher when compared with $/ \mathrm{t}, \mathrm{z}, \mathrm{d} /$.
Three $y$-intercept mean comparisons showed nonsignificant differences: /d/ versus $/ z /, / d / @$ burst versus $/ \mathrm{t} /$, and $/ \mathbf{n} /$ versus $/ \mathrm{z} /$. However, unlike the results reported in Fowler (1994), slope and $y$-intercept mean differences for $/ d /$ and $/ z /$ were found to be statistically nonsignificant.

Other variables of interest in comparing locus equations across manner classes are $R^{2}$ and standard error of estimate $(S E)$. The $R^{2}$ statistic indicates how much variance in the dependent variable ( $F 2$ onset) can be accounted 
Table 2

Results of Post Hoc Tests For Determining Differences Among Means

\begin{tabular}{|c|c|c|c|c|c|c|}
\hline & $/ \mathrm{d} /$ & $/ \mathrm{d} / *$ & $/ \mathrm{t} /$ & $/ \mathrm{n} /$ & $|z|$ & $/ \mathrm{s} /$ \\
\hline \multicolumn{7}{|c|}{ Slope } \\
\hline$M$ & .403 & .261 & .234 & .480 & .378 & .569 \\
\hline$/ \mathrm{d} /$ & & $\dagger$ & $\dagger$ & n.s. & n.s. & $\dagger$ \\
\hline$/ \mathrm{d} / *$ & & & n.s. & $\dagger$ & $\dagger$ & $\dagger$ \\
\hline$/ \mathrm{t} /$ & & & & $\dagger$ & $\dagger$ & $\dagger$ \\
\hline$/ \mathbf{n} /$ & & & & & $\dagger$ & n.s. \\
\hline$|\mathbf{z}|$ & & & & & & $\dagger$ \\
\hline tor & & & & & & \\
\hline \multicolumn{7}{|c|}{$y$-Intercept } \\
\hline$M$ & 1117 & 1418 & 1495 & 899 & 942 & 643 \\
\hline$/ \mathrm{d} /$ & & $\dagger$ & $\dagger$ & $\dagger$ & n.s. & $\dagger$ \\
\hline$/ \mathrm{d} / *$ & & & n.s. & $\dagger$ & $\dagger$ & $\dagger$ \\
\hline$/ t /$ & & & & $\dagger$ & $\dagger$ & $\dagger$ \\
\hline$/ \mathrm{n} /$ & & & & & n.s. & $\dagger$ \\
\hline $\begin{array}{l}\mid \mathrm{z} / \\
/ \mathrm{s} /\end{array}$ & & & & & & $\dagger$ \\
\hline
\end{tabular}

Note- $y$-intercept is in Hertz. $* / d /$ measured within aspiration interval. ${ }^{\dagger} t<.01$.

for by the independent variable, $F 2$ vowel, and the $S E$ statistic reflects the standard deviation of the residuals or the average distance $(\mathrm{Hz})$ of each data point from the regression line. The $S E$ provides an indication of the overall linearity of the locus equation data points. Table 3 shows $R^{2}$ and $S E$ values for all speakers across manner class categories. Across all consonants, the group mean $R^{2}$ was .79 and group mean $S E$ was $68 \mathrm{~Hz}$. Stops and the nasal had slightly lower $R^{2}$ values compared with fricatives (.77 vs. .83), but smaller $S E$ s (65 vs. $72.5 \mathrm{~Hz})$. In general, all locus equations, regardless of manner class, were characterized as having tightly clustered data points around each regression function.

An ANOVA performed on the $R^{2}$ values yielded a significant effect for consonant manner class $[F(21,105)=$ $20.3, p<.0001]$. Subsequent comparisons of mean differences using the Scheffé showed significant differences primarily involving comparisons of voiceless aspirated $/ t /$ and $/ \mathrm{d} / @$ burst $(.67$ and .73$)$ with every other consonant $(/ \mathrm{d} /=$ $.86, / \mathrm{n} /=.83, / \mathrm{z} /=.80, / \mathrm{s} /=.86)$. An ANOVA performed on the $S E$ values yielded a significant effect for consonant manner class $[F(21,105)=15.35, p<.0001]$. Subsequent comparisons showed significant differences when $/ \mathbf{n} /$ and /s/ $(83$ and $82 \mathrm{~Hz})$ were compared with $/ \mathrm{d} /(59 \mathrm{~Hz}), / \mathrm{d} / @$ burst $(57 \mathrm{~Hz}), / \mathrm{t} /(62 \mathrm{~Hz})$, and $/ \mathrm{z} /(63 \mathrm{~Hz})$.

\section{Locus Equation Space}

The post hoc tests following the MANOVA showed that some slope and $y$-intercept differences within the coronal group were significant and others were not. Another method of determining similarity/dissimilarity of locus equation plots among the diverse coronals examined in this study is to use a more macro approach - plotting slope versus $y$-intercept across a wide assortment of $\mathrm{CV} / \mathrm{t} /$ tokens that include labial, alveolar, and velar obstruents. If alveolars, as a group, do not overlap with labials and velars, the case is further strengthened that locus equation coefficients can serve as general phonetic descriptors for place of articulation across manner classes. In Figure 3 are plotted slopes (along the $x$-axis) and $y$-intercepts (along the $y$-axis) obtained from the 22 speakers producing the five consonantal categories of the present study. These

Table 3

Summary of $R^{2}$ and Standard Error of Estimate $(S E)$ for Locus Equations for Each Consonantal Manner Class Across All Speakers

\begin{tabular}{|c|c|c|c|c|c|c|c|c|c|c|c|c|}
\hline \multirow[b]{2}{*}{ Speaker } & \multicolumn{2}{|c|}{$/ \mathrm{d} /$} & \multicolumn{2}{|c|}{ /d/@burst } & \multicolumn{2}{|c|}{$/ \mathrm{t} /$} & \multicolumn{2}{|c|}{$\ln /$} & \multicolumn{2}{|c|}{$|z|$} & \multicolumn{2}{|c|}{$/ \mathrm{s} /$} \\
\hline & $R^{2}$ & $S E$ & $R^{2}$ & $S E$ & $R^{2}$ & $S E$ & $R^{2}$ & $S E$ & $R^{2}$ & $S E$ & $R^{2}$ & $S E$ \\
\hline 1 & .88 & 59 & .73 & 48 & .58 & 44 & .90 & 71 & .75 & 58 & .84 & 95 \\
\hline 2 & .88 & 79 & .82 & 73 & .71 & 99 & .83 & 118 & .81 & 86 & .89 & 103 \\
\hline 3 & .84 & 53 & .60 & 56 & .80 & 46 & .86 & 55 & .73 & 47 & .85 & 64 \\
\hline 4 & .88 & 36 & .66 & 44 & .58 & 39 & .76 & 94 & .85 & 64 & .93 & 67 \\
\hline 5 & .82 & 63 & .75 & 52 & .57 & 50 & .86 & 86 & .82 & 60 & .85 & 78 \\
\hline 6 & .90 & 61 & .74 & 65 & .91 & 43 & .87 & 83 & .87 & 64 & .93 & 66 \\
\hline 7 & .86 & 89 & .82 & 74 & .80 & 53 & .84 & 124 & .84 & 55 & .91 & 82 \\
\hline 8 & .85 & 64 & .75 & 59 & .75 & 53 & .80 & 90 & .80 & 71 & .82 & 115 \\
\hline 9 & .77 & 62 & .86 & 40 & .71 & 67 & .86 & 82 & .86 & 69 & .88 & 74 \\
\hline 10 & .89 & 60 & .81 & 51 & .61 & 78 & .74 & 80 & .77 & 81 & .87 & 81 \\
\hline 11 & .90 & 33 & .70 & 45 & .47 & 76 & .85 & 54 & .81 & 34 & .86 & 43 \\
\hline 12 & .78 & 79 & .59 & 85 & .66 & 61 & .77 & 105 & .76 & 69 & .77 & 103 \\
\hline 13 & .93 & 50 & .69 & 65 & .84 & 72 & .88 & 69 & .87 & 71 & .90 & 79 \\
\hline 14 & .89 & 67 & .83 & 59 & .71 & 58 & .70 & 131 & .63 & 89 & .77 & 136 \\
\hline 15 & .91 & 53 & .80 & 56 & .91 & 36 & .89 & 71 & .90 & 42 & .91 & 60 \\
\hline 16 & .90 & 49 & .78 & 58 & .74 & 51 & .81 & 79 & .90 & 41 & .89 & 65 \\
\hline 17 & .84 & 52 & .64 & 56 & .75 & 55 & .84 & 62 & .85 & 39 & .91 & 47 \\
\hline 18 & .93 & 64 & .84 & 59 & .82 & 74 & .90 & 80 & .85 & 84 & .87 & 129 \\
\hline 19 & .86 & 46 & .56 & 55 & .64 & 81 & .90 & 54 & .89 & 42 & .83 & 73 \\
\hline 20 & .82 & 48 & .47 & 59 & .34 & 74 & .83 & 63 & .59 & 79 & .74 & 76 \\
\hline 21 & .82 & 56 & .70 & 45 & .23 & 77 & .83 & 73 & .71 & 65 & .76 & 83 \\
\hline 22 & .80 & 75 & .86 & 52 & .57 & 74 & .82 & 96 & .70 & 83 & .86 & 75 \\
\hline$M$ & .86 & 59 & .73 & 57 & .67 & 62 & .83 & 83 & .80 & 63 & .86 & 82 \\
\hline$S D$ & .046 & 14 & .106 & 11 & .17 & 16 & .054 & 22 & .085 & 17 & .056 & 24 \\
\hline
\end{tabular}


Place of Articulation Across Manner Classes in Locus Equation Coordinates

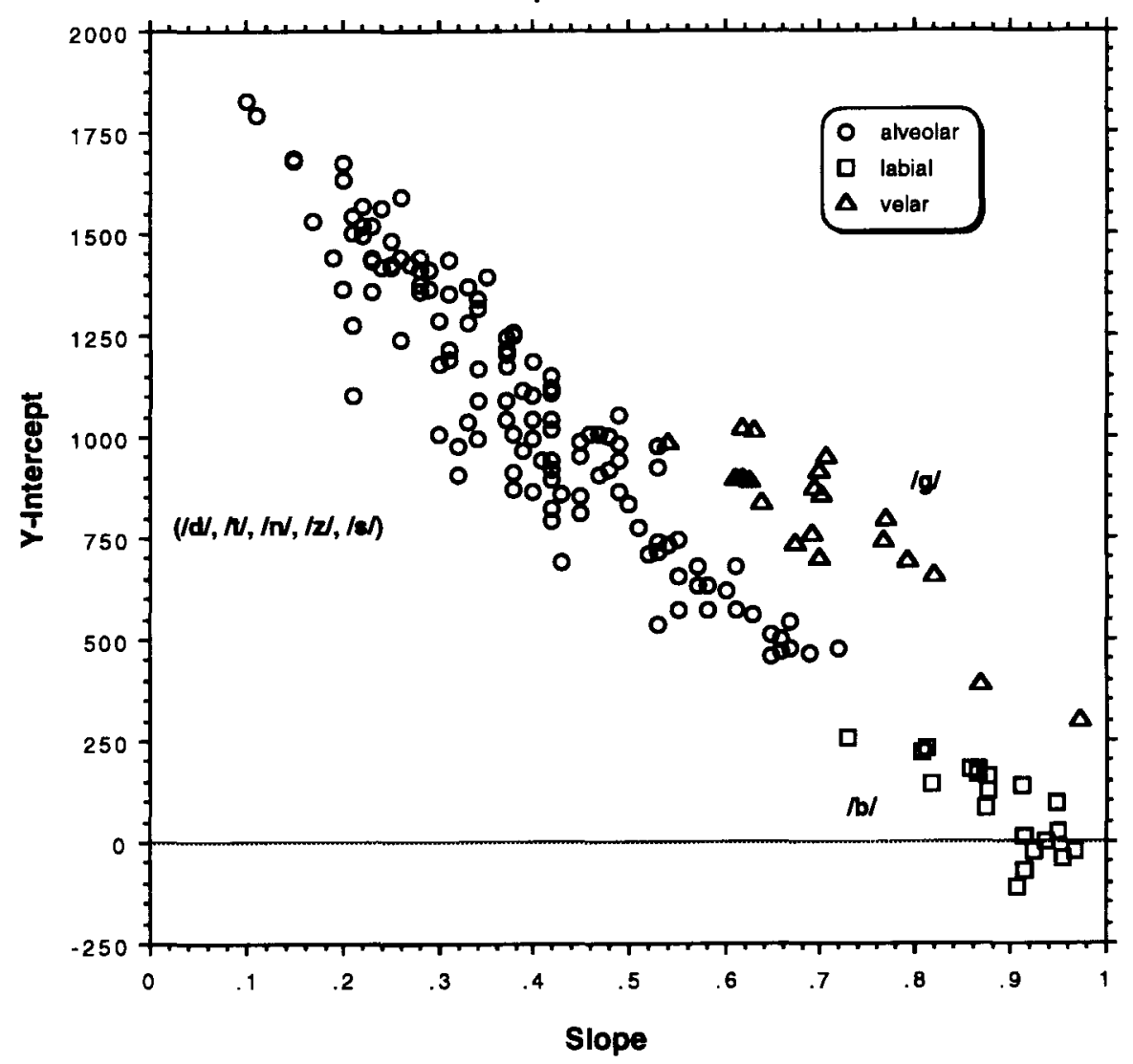

Figure 3. Scatterplot of slope and $y$-intercept coordinates across 22 speakers of this study producing the set of coronal consonants $(/ d, t, n, z, s /)$. Locus equation coordinates from 20 speakers producing initial labial $/ \mathrm{b} / \mathrm{V} / \mathrm{t} /$ and velar $/ g / V / t /$ tokens (data from Sussman et al., 1991) are shown to compare place of articulation in higher order locus equation acoustic space.

coordinates represent a large alveolar cluster spanning a voiced stop (showing both versions of $F 2$ onset for $/ \mathrm{d} /$ ), a voiceless stop, a nasal, and voiced and voiceless sibilant fricatives. Since only alveolars were obtained from the speakers of this study, it was necessary to use data obtained from other speakers, from a prior locus equation study, in order to compare labials and velars with the alveolar group. Locus equation coefficients (slopes and $y$ intercepts) obtained from 20 speakers, each producing $50 / \mathrm{b} / \mathrm{V} / \mathrm{t} /$ and $50 / \mathrm{g} / \mathrm{V} / \mathrm{t} /$ tokens $(5$ repetitions per stop across the same 10 vowels) were entered into the scatterplot of Figure 3 (data taken from Sussman et al., 1991). It is felt that this cross comparison of locus-equationderived place data, though obtained from different speakers, is justified for several reasons. First, the great majority of tokens in both studies were measured by the same investigator (H.M.S.). Second, all contexts and conditions were identical $-\mathrm{CV} / \mathrm{t} / \mathrm{s}$ produced at a normal rate and loudness level, in the carrier sentence "Say CV/t / again," with the identical set of 10 vowels in medial position. Third, all recording, sampling, amplification, and software analysis procedures were identical to those used in the present study. Fourth, the mean /d/ slope and $y$-intercept from Sussman et al. (1991) were very close to those found in the present study. Last, locus equation place of articulation results similar to those used to construct Figure 3 have now been successfully replicated by several investigators across several laboratories (e.g., Bakran \& Mildner, 1995; Celdran \& Villalba, 1995; Chinnery, Docherty, \& Walshaw, 1995; Eek \& Meister, 1995; Fowler, 1994).

Three distinct and nonoverlapping clusters can be seen in Figure 3. Despite the relatively large variation in both slope and $y$-intercept values across speakers within the varied alveolar cluster spanning several manner classes, alveolars (circles) are distinct from velar /g/ (triangles) and labial/b/ (squares) clusters. The range of slope values within the alveolar group is quite large (from a low of .10 for aspirated $/ \mathrm{t} /$ (Speaker 4) to a high of $.72 \mathrm{for} / \mathrm{s} /$ (Speaker 18). This large slope range can be attributed to the different measurement loci taken for $F 2$ onset. $F 2$ onsets taken immediately following the burst for $/ \mathrm{t} / \mathrm{evi}$ dence minimum coarticulation in comparison with $F 2$ onsets taken at the first glottal pulse of the vowel for $/ \mathrm{s} /$, which contains a lengthy frication interval. The latter 
condition (fricative /s/) results in "artificially" elevated slopes, because the two frequency measures, "onset" and midpoint, are highly similar. What is most interesting about this diversity of slope/coarticulation differences across manner class categories is that, despite these large slope variations, as a class, alveolars do not overlap in higher order locus equation acoustic space, with labials and velars. Labials and velars characteristically exhibit relatively more coarticulation than alveolars, regardless of manner class. There has never been, to our knowledge, a report of locus equation slopes for alveolars that have exceeded those characterizing labials or velars.

\section{Discriminant Analysis}

Another procedure to quantify how well locus equation coefficients serve as general place descriptors is to perform a discriminant analysis using slope and $y$-intercept as predictor variables for place of articulation category membership. The primary objective in this analysis was to see how the various coronals would be categorized: would they be grouped within a "generic" alveolar place group, or would some find categorical membership in velar or labial groups? The number of cases for the alveolar group was 132 (6 consonants $\times 22$ speakers). The results of this analysis are shown in Table 4 . Of the total cases (132), $115(87.1 \%)$ were correctly classified as alveolars. Seventeen cases were incorrectly classified as velars $(12.9 \%)$. The overall percent correct classification across the three groups was $87.4 \%$.

\section{Voicing Differences}

An unexpected manner class difference was seen when $/ z /$ and $/ \mathrm{s} /$ were compared. Figure 4 shows slope values for $/ \mathrm{s} /$ and $/ \mathrm{z} /$ for each speaker. It can be seen that slopes for $/ \mathrm{s} /$ are consistently higher than that of $/ \mathrm{z} /$. The greater slopes for $/ \mathrm{s} /($ mean $=.57)$ than for $/ \mathrm{z} /($ mean $=.38)$ seem to indicate that the tongue was more nearly in position for the upcoming vowel during the constriction of $/ \mathrm{s} /$ than it was for $/ z / . F 2$ onset points, taken at the first glottal pulse of the vowel, were, in theory, identical for both fricatives. In general, voiceless fricatives are known to be longer than voiced fricatives (Baum \& Blumstein, 1987; Crystal \& House, 1988). Jongman (1989) reported mean durations of frication noise of $188 \mathrm{msec}$ for $/ \mathrm{s} /$ and $152 \mathrm{msec}$ for $/ \mathrm{z} /$. By virtue of the longer noise interval for $/ \mathrm{s} /$ than for $/ \mathrm{z} /, F 2$ onsets, though technically measured at the initial glottal pitch period of the vowel, were more

Table 4

Results of Discriminant Analysis Showing Percent Classification of Place of Articulation (Predictor Variables $=$ Slope and $y$-Intercept)

\begin{tabular}{|c|c|c|c|c|c|c|c|}
\hline \multirow[b]{3}{*}{ Actual Group } & \multirow[b]{3}{*}{ No. Cases } & \multicolumn{6}{|c|}{ Predicted Group Membership } \\
\hline & & \multicolumn{2}{|c|}{ Labial } & \multicolumn{2}{|c|}{ Alveolar } & \multicolumn{2}{|c|}{ Velar } \\
\hline & & $\%$ & $\bar{n}$ & $\%$ & $n$ & $\%$ & $n$ \\
\hline Labial & 20 & 95 & 19 & & 0 & 5 & 1 \\
\hline Alveolar & 132 & & 0 & 87.1 & 115 & 12.9 & 17 \\
\hline Velar & 20 & 15 & 3 & 5 & 1 & 80 & 16 \\
\hline
\end{tabular}

like "steady state" measures for $/ \mathrm{s} / \mathrm{V} / \mathrm{t} /$ than for $/ \mathrm{z} / \mathrm{V} / \mathrm{t} /$ tokens. With $F 2$ onsets more closely corresponding to $F 2$ midpoints, a greater degree of $\mathrm{CV}$ coarticulation is realized for $/ \mathrm{s} /$ than for $/ \mathrm{z} /$ (and the other alveolar obstruents) with resultant higher slopes.

\section{DISCUSSION}

Locus equations were derived across a varied set of consonantal manner classes to determine their generality as a phonetic descriptor of consonantal place of articulation. Five consonants - a voiced stop $(/ \mathrm{d} /)$, a voiceless aspirated stop $(/ \mathrm{t} /)$, a nasal $(/ \mathrm{n} /)$, a voiced fricative $(/ \mathrm{z} /)$, and a voiceless fricative $(/ \mathrm{s} /)$-were produced in syllableinitial position preceding 10 vowel contexts. Nonsignificant effects were found for slope means among the three voiced obstruents $/ \mathrm{d} /, \mid \mathrm{z} /$, and $/ \mathrm{n} /$, and additionally between $/ \mathrm{d} /$ and $/ \mathrm{t} /$ when $F 2$ onset frequencies were measured, not at the first glottal pulse following release, but rather well within the aspiration interval, as close to the release burst as possible. The results of this study call into question the conclusion of Fowler (1994) claiming that locus equations could not serve as a general descriptor of place of articulation because /d/ and / $\mathrm{z} /$ slopes (.47 and .42 respectively in her data) were found to be statistically different in a group of 10 speakers.

Only /s/ evidenced significantly different slope $/ y$ intercepts from the rest of the coronals (except in comparison with the slope for $/ \mathbf{n} /$ ). The significantly higher slopes for/s/are better explained, at this point, by invoking a measurement limitation rather than an underlying phonetic-based explanation. By taking $F 2$ onsets at the first glottal pulse of the vowel following the long frication interval for $/ \mathrm{s} /$, all of the transition movement of $F 2$ was already completed. Hence, the $F 2$ onset frequencies were strongly conditioned by the vowel midpoint, rather than their reflecting an actual consonantal onset locus. This resulted in much higher slope values than would be the case if onsets were able to be assessed at the earliest possible moment within the lengthy frication interval. Unfortunately, it was not possible to ascertain this $F 2$ onset point at the beginning of frication with any consistency across all vowel contexts. ${ }^{3}$

The basic homogeneity of locus equation coefficients for the entire coronal set was also seen in other formatsscatterplots of slope and $y$-intercept values across speakers and a discriminant analysis. When the five obstruents constituting the study were compared with labial and velar locus equation coefficients, three distinct clusters of coordinates emerged with clear separation as a function of place affiliation. Despite an extensive range in both slope and $y$-intercept values, the coronals occupied a different portion of locus equation acoustic space than did labials and velars. Only $/ \mathrm{s} /$ coordinates, with relatively high slopes (between .50 and .70) were, in some cases, close to, but not overlapping with, velar coordinates. In the discriminant analysis, using slopes and $y$-intercepts as predictor variables, over $87 \%$ ( 115 of 132 cases) of the total coronal group, comprising voiced and voiceless stops, a nasal, 


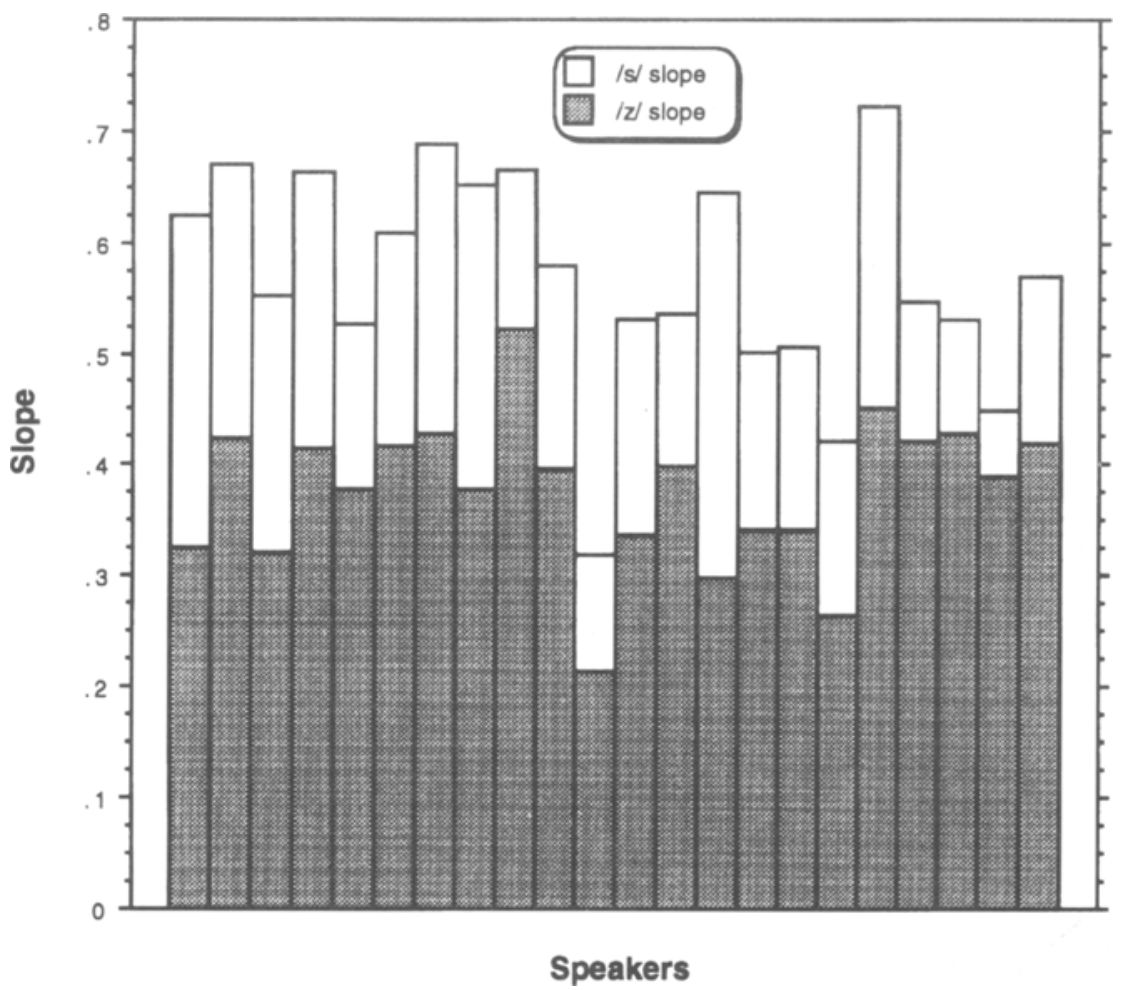

Figure 4. Slope values for /z/ versus /s/ across 22 speakers.

and voiced and voiceless fricatives, were correctly categorized as alveolars.

A stop + vowel sequence and a fricative + vowel sequence represent vastly different articulatory gestures and concomitant acoustic correlates. The two manner classes would be placed on opposite ends of a variety of phonetically based continua. Stops are characterized by a short, transient sound source, and fricatives, by a long continuant noise sound source. Stop + vowel concatenations are the most universally encoded CVs across languages. Their unique and complex acoustic overlap create the underlying basis for the noninvariance problem in speech perception (Liberman, Cooper, Shankweiler, \& StuddertKennedy, 1967). Sibilant fricative + vowels, such as $/ \mathrm{s} /$ and $/ z /$, on the other hand, represent one of the rare cases in the speech code where isomorphism can be said to best exist between a physical aspect of the sound and a perceived phoneme. The frication of $/ \mathrm{s} /$ in sat can be spliced away and placed in front of $i t$ to yield the perception of sit. The same cannot be said for bat and bit. The fricative spectra of $/ \mathrm{s} /$ and $/ z /$, by itself, has been found to be the necessary and sufficient cue for perception (Harris, 1958; Heinz \& Stevens, 1961; Jongman, 1989). What is most noteworthy about the results of this study is the fact that, despite these drastic differences in production mechanics, acoustic characteristics, and degree of encodedness, the locus equation coefficients for alveolars belonging to these diverse manner classes are more similar than dissimilar. Moreover, they are all, as a group, sufficiently contrastive to the other places of articulation, such as labials and velars. Rather than stress small differences in locus equation slopes (viz., Fowler's /d/ vs. / $\mathrm{z}$ / comparison), the emphasis should be on the remarkable similarity that they possess, as a group, despite nearly diametrically opposed phonetic characteristics.

It is not completely surprising, however, that the acoustic signal produced by a set of articulations entailing highly similar closure-opening gestures yield relatively similar locus equation plots. Occlusions/constrictions of the tongue on the alveolar ridge, followed by release into a vowel, are encoded by similar dynamics of the $F 2$ transition. Since locus equation coordinates are compact parameterizations of the onset and midvowel frequencies of $F 2$, it is to be expected that place similarities would be captured by locus equation analyses. If the temporal measurement point of $F 2$ onset could be standardized and phonetically matched across the varied manner classes, as they were in comparing / $/$ and /d/@ burst, then an even closer correspondence of locus equation slopes would no doubt be obtained, with slopes more closely resembling those seen with voiceless aspirated $/ \mathrm{t} /$.

The overall results of this study can be taken to support the contention that locus equations can indeed be used as a general phonetic descriptor of place of articulation. As a class, alveolar obstruents, even across phonetically diverse manner classes, will have lower slopes (less CV coarticulation) characterized by more stable onset loci than will labial and velar places of articulation. 


\section{REFERENCES}

Bakran, J., \& Mildner, V. (1995). Effect of speech rate and coarticulation strategies on the locus equation determination. Proceedings of the XIIth International Congress of Phonetic Sciences, 1, 26-29.

Baum, S. R., \& Blumstein, S. E. (1987). Preliminary observations on the use of duration as a cue to syllable-initial voicing in English. Journal of the Acoustical Society of America, 82, 1073-1077.

Blumstein, S. E., \& Stevens, K. N. (1979). Acoustic invariance in speech production: Evidence from measurements of the spectral characteristics of stop consonants. Journal of the Acoustical Society of America, 66, 1001-1017.

Blumstein, S. E., \& Stevens, K. N. (1980). Perceptual invariance and onset spectra for stop consonants in different vowel environments. Journal of the Acoustical Society of America, 67, 648-662.

Carré, R., \& Mrayati, M. (1992). Distinctive regions in acoustic tubes: Speech production modeling. Journal d'Acoustique, 5, 141-159.

Celdran, E. M., \& Villalba, X. (1995). Locus equations as a metric for place of articulation in automatic speech recognition. Proceedings of the XIIIth International Congress of Phonetic Sciences, 1, 30-33.

Chennoukh, S., Carré, R., \& Lindblom, B. (1995, May-June). On the "locus equation" and its relation with consonant place of articulation. Paper presented at 129 th meeting of the Acoustical Society of America, Washington, DC.

Chinnery, C., Docherty, G. J., \& Walshaw, D. (1995). Formant locus equations and coarticulation in dyspaxic speech. Proceedings of the XIIIth International Congress of Phonetic Sciences, 1, 90-93.

Clements, G. N. (1985). The geometry of phonological features. Phonology Yearbook, 2, 225-252.

CRYSTAL, T. H., \& House, A. S. (1988). A note on the durations of fricatives in American English. Journal of the Acoustical Society of America, 84, 1932-1935.

Dorman, M. F., Studdert-Kennedy, M., \& Raphael, L. J. (1977). Stop-consonant recognition: Release bursts and formant transitions as functionally equivalent, context-dependent cues. Perception \& Psychophysics, 22, 109-122.

EEK, A., \& MeIsTER, E. (1995). The perception of stop consonants: Locus equations and spectral integration. Proceedings of the XIIIth International Congress of Phonetic Sciences, 1, 18-21.

FowLER, C. A. (1994). Invariants, specifiers, cues: An investigation of locus equations as information for place of articulation. Perception \& Psychophysics, 55, 597-610.

FRUCHTER, D. (1994). Perceptual significance of locus equations. Journal of the Acoustical Society of America, 95, 2977.

FURUI, S. (1986). On the role of spectral transition for speech perception. Journal of the Acoustical Society of America, 80, 1016-1025.

HaRrIs, K. S. (1958). Cues for the discrimination of American English fricatives in spoken syllables. Language \& Speech, 1, 1-7.

Hasegawa-Johnson, M. (1995). Burst spectral measures and formant frequencies can be used to accurately discriminate place of articulation. Journal of the Acoustical Society of America, 98, 2890.

Heinz, J. M., \& Stevens, K. N. (1961). On the properties of voiceless fricative consonants. Journal of the Acoustical Society of America, 33, 589-596.

Hinton, G. E., \& LANG, K. J. (1988). The development of the timedelay neural network architecture for speech recognition (Tech. Rep. No. CMU-CS, 88-112). Carnegie Mellon University.

JoNGMAN, A. (1989). Duration of frication noise required for identification of English fricatives. Journal of the Acoustical Society of America, 85, 1718-1725.

KEWLEY-PORT, D. (1983). Time-varying features as correlates of place of articulation in stop consonants. Journal of the Acoustical Society of America, 73, 322-335.

KRULL, D. (1989). Consonant-vowel coarticulation in spontaneous speech and in reference words. PERILUS, 10, 101-105. Stockholm: University of Stockholm, Institute of Linguistics.

LAHIRI, A., GewirTh, L., \& BlumsteIN, S. E. (1984). A reconsideration of acoustic invariance for place of articulation in diffuse stop consonants: Evidence from a cross-language study. Journal of the Acoustical Society of America, 76, 391-404.
Liberman, A. M., Cooper, F. S., Shankweiler, D. P., \& StuddertKennedy, M. (1967). Perception of the speech code. Psychological Review, 74, 431-461.

LiNDBLOM, B. (1963). On vowel reduction (Report No. 29). Stockholm: Royal Institute of Technology, Speech Transmission Laboratory.

McDermott, E., \& Katagiri, S. (1988). Phoneme recognition using Kohonen's learning vector quantization. Paper presented at ATR Workshop on Neural Networks and Parallel Distributed Processing, Osaka, Japan.

Nossair, Z. B., \& Zahorian, S. A. (1991). Dynamic spectral shape features as acoustic correlates for initial stop consonants. Journal of the Acoustical Society of America, 89, 2978-2991.

Ohde, R. N., Haley, K. L., Vorperian, H. K., \& Mcmahon, C. W. (1995). A developmental study of the perception of onset spectra for stop consonants in different vowel environments. Journal of the Acoustical Society of America, 97, 3800-3812.

RECASENS, D. (1989). Long range coarticulatory effects for tongue dorsum contact in VCVCV sequences. Speech Communication, 8, 293-307.

Sussman, H. M. (1994). The phonological reality of locus equations across manner class distinctions: Preliminary observations. Phonetica, 51, 119-131.

Sussman, H. M., Fruchter, D., \& Cable, A. (1995). Locus equations derived from compensatory articulation. Journal of the Acoustical Society of America, 97, 3112-3124.

Sussman, H. M., Hoemeke, K., \& Ahmed, F. (1993). A cross-linguistic investigation of locus equations as a relationally invariant descriptor for place of articulation. Journal of the Acoustical Society of America, 94, 1256-1268.

Sussman, H. M., Hoemeke, K., \& McCaffrey, H.A. (1992). Locus equations as an index of coarticulation for place of articulation distinctions in children. Journal of Speech \& Hearing Research, 35, 769-781.

Sussman, H. M., Mccaffrey, H. A., \& Matthews, S. A. (1991). An investigation of locus equations as a source of relational invariance for stop place categorization. Journal of the Acoustical Society of America, 90, 1309-1325.

TANK, D. W., \& HoPfIELD, J. J. (1988). Learning time-delayed connections in a speech recognition circuit. Paper presented at Neural Networks for Computing Conference, Snowbird, UT.

Waibel, A., Hanazawa, T., Hinton, G., Shikano, K., \& Lang, K. (1987). Phoneme recognition using time-delay neural networks (Tech. Rep. No. TR-1-006). Kyoto, Japan: ATR Interpreting Telephony Research Laboratories.

Walley, A. C., \& Carrell, T. D. (1983). Onset spectra and formant transitions in the adult's and child's perception of place of articulation in stop consonants. Journal of the Acoustical Society of America, 73, 1011-1022.

WATROUS, R. L. (1988). Speech recognition using connectionist networks. Unpublished doctoral dissertation, University of Pennsylvania.

\section{NOTES}

1. By "phonetically valid," we simply mean that if an aspirated stop is to be compared with an unaspirated stop in terms of locus equation plots, the measurement points for $F 2$ onset and $F 2$ vowel should correspond as closely as possible.

2. Two other post hoc tests were administered to see whether less conservative measures might change the results. Using the Fisher PLSD, /d/ and $/ z /$ slope means were not significantly different $(p=.28)$; using the Bonferroni/Dunn, $/ d /$ and $/ z /$ slope means were also not significantly different $(p=.28)$. All three post hoc tests also showed nonsignificant mean differences between $/ \mathrm{d} / @$ burst and $/ \mathrm{t} /$.

3 . It should be borne in mind that locus equations were originally devised to capture the highly encoded and rapid CV transitions of stop + vowel utterances and were not intended for continuants such as $/ \mathrm{s} /$ and $/ z /$, which entail $F 2$ onset measurement points well beyond those obtainable for stops.

(Manuscript received July 27, 1995 ; revision accepted for publication December 14, 1995.) 